A
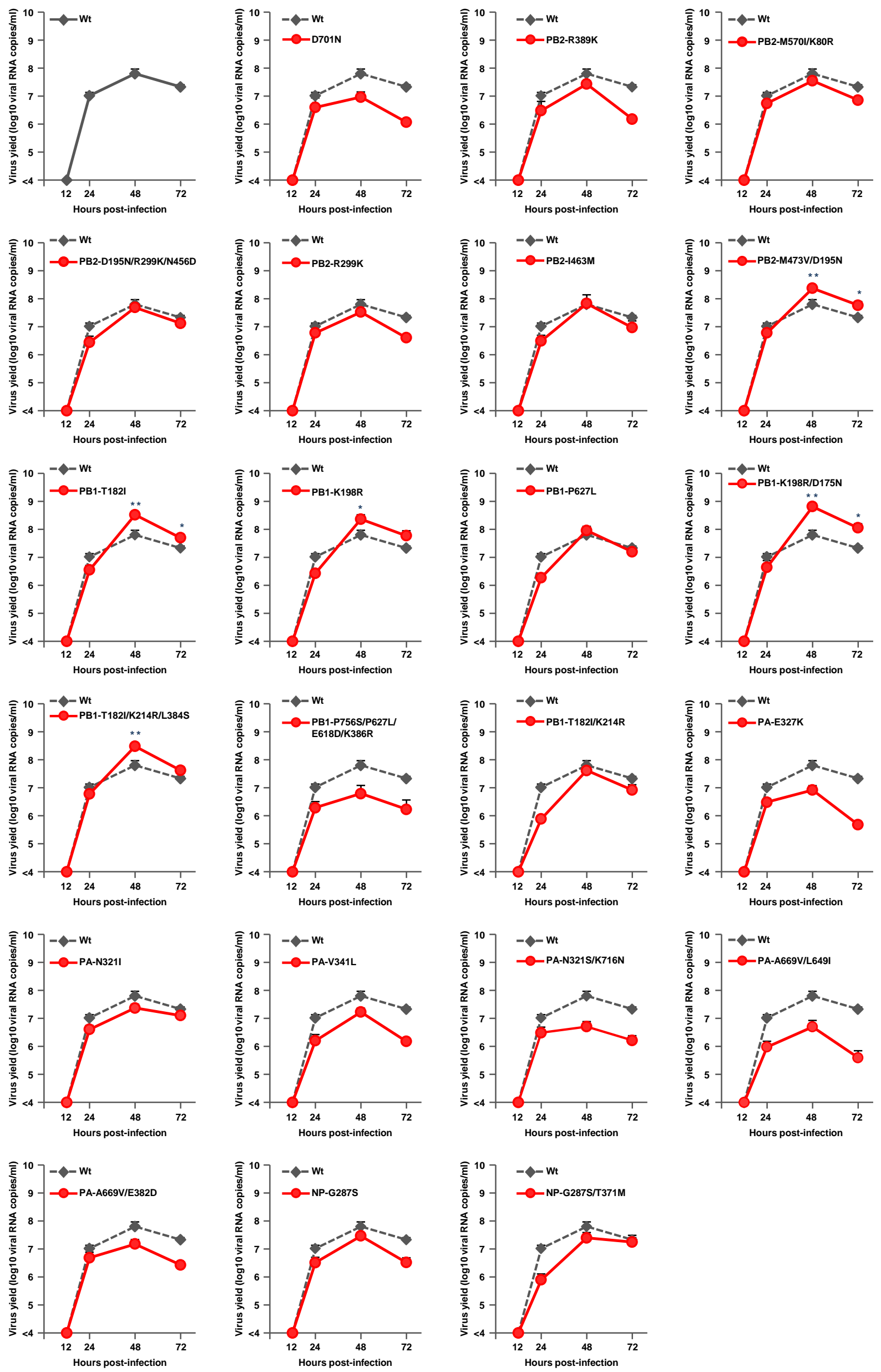


\section{A (Continued)}
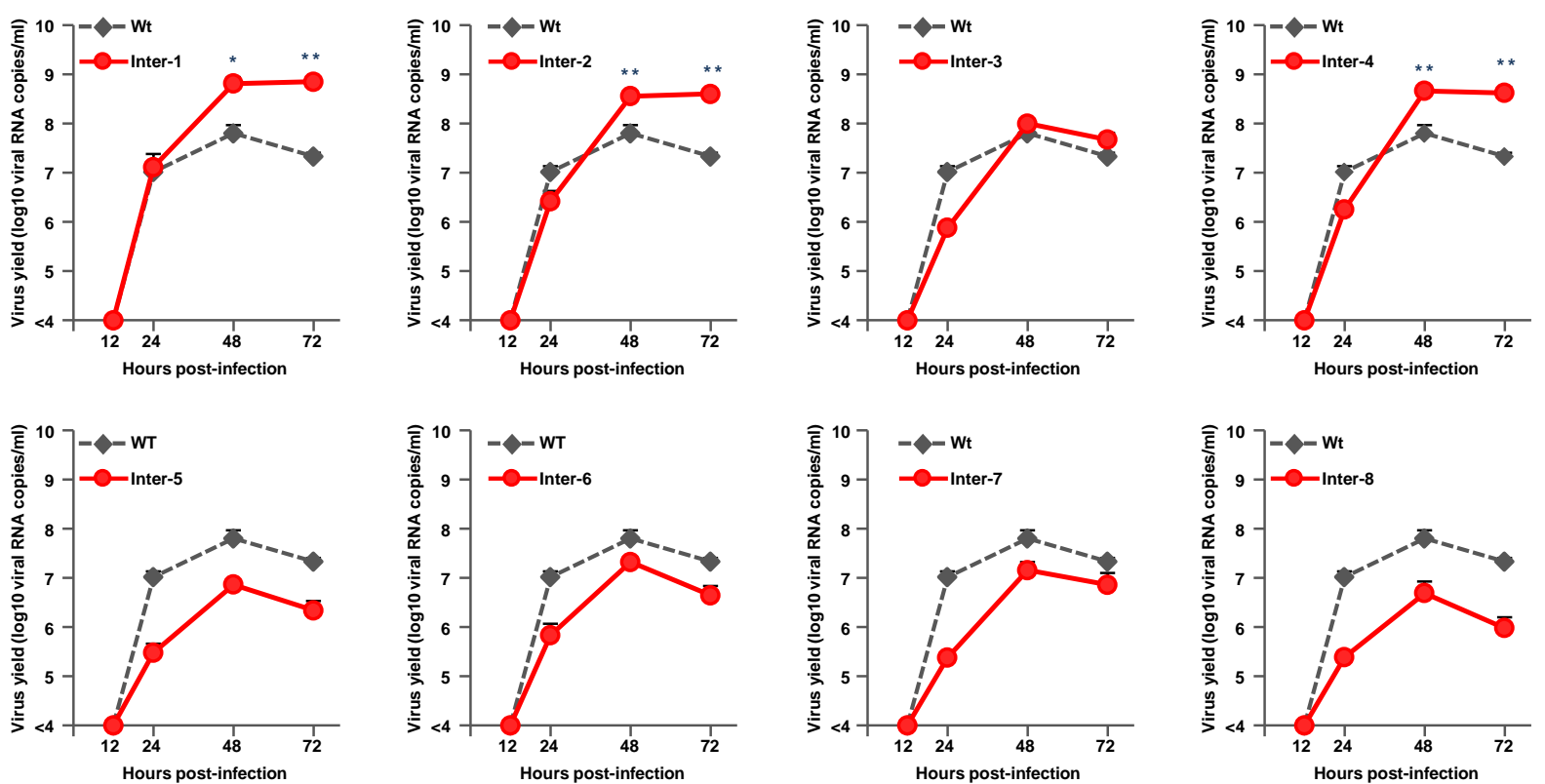

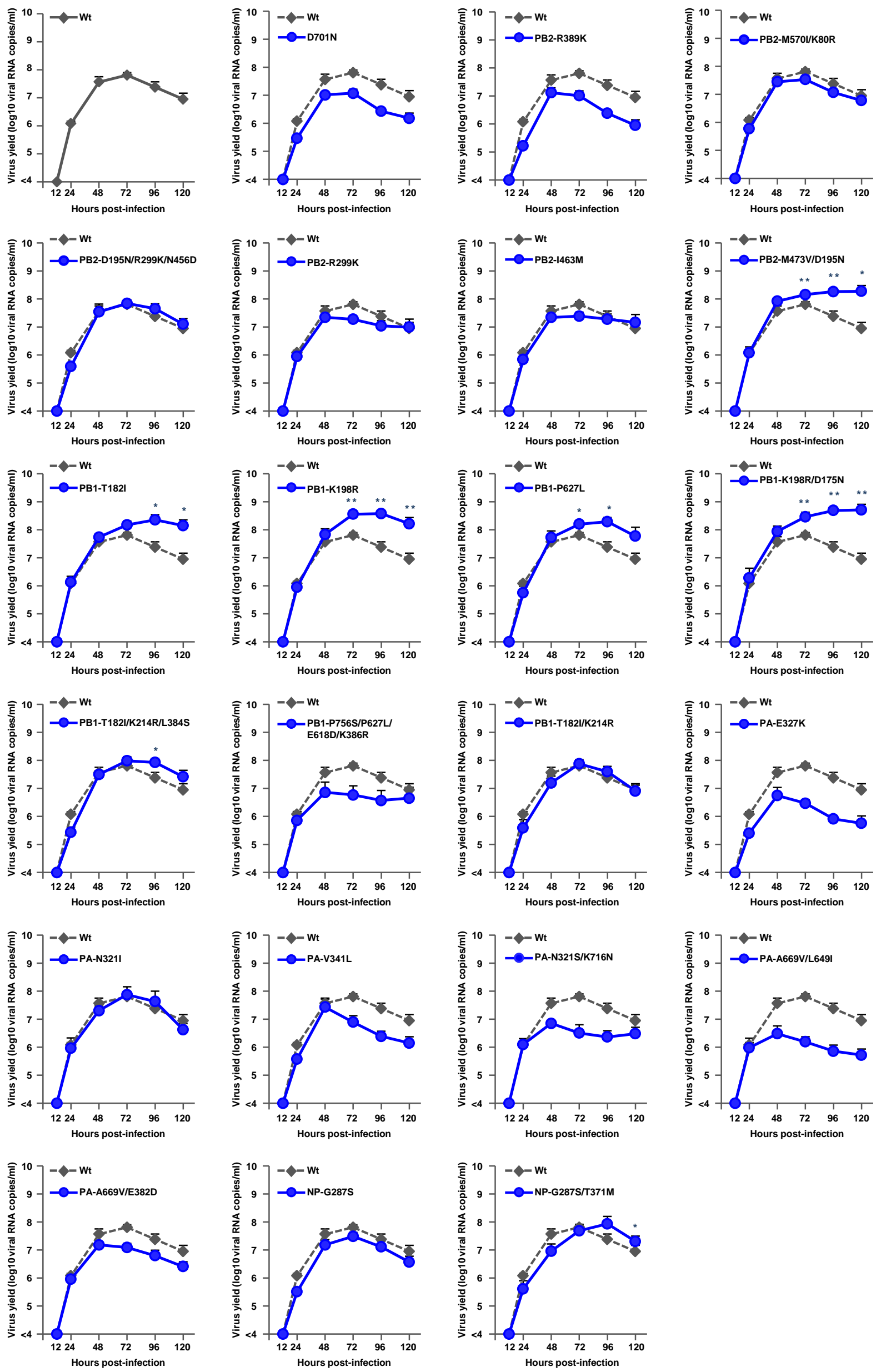


\section{B (Continued)}
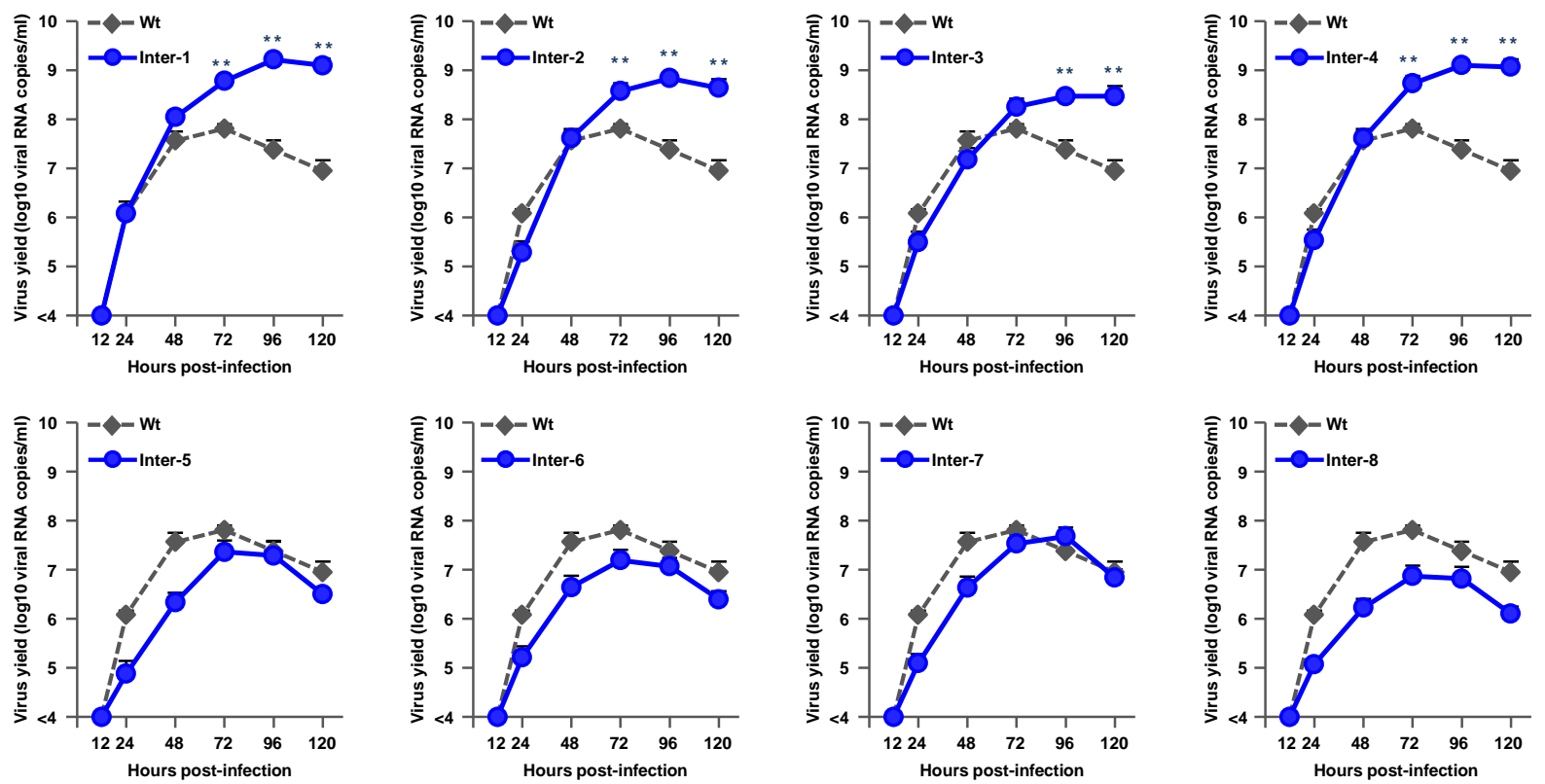